\title{
SISTEM INFORMASI MANAJEMEN DAN AKUNTANSI BARANG MILIK NEGARA PADA DINAS PERINDUSTRIAN DAN PERDAGANGAN DAERAH PROVINSI SULAWESI UTARA
}

\author{
I Gusti Agung Sri Wirananda \\ Jurusan Akuntansi, Fakultas Ekonomi dan Bisnis, Universitas Sam Ratulangi, Jl. Kampus Bahu, Manado, \\ 95115, Indonesia \\ E-mail : asriwirananda@gmail.com
}

\begin{abstract}
Administration of state-owned goods is one of the important activities to account for the use of the state budget. In its implementation, BMN administration activities are supported by the implementation of the SIMAK-BMN application which functions to assist in the preparation of balance sheets and reports on state property. As the agency authorized to administer/and or use BMN at the UAKPB level, the Regional Industry and Trade Office of North Sulawesi Province must administer BMN referring to PMK No. 181/PMK.06/2016 concerning Administration of BMN to produce accurate recording and reporting of state assets. In addition, by combining information systems, proper administration procedures, and accuracy in running the system, it is hoped that errors in the BMN administration process such as human errors can be minimized.
\end{abstract}

Keywords: information systems; state property; procedure

\section{PENDAHULUAN}

Perkembangan teknologi dan informasi secara pesat di era saat ini telah mempengaruhi berbagai aktivitas pekerjaan. Hal ini terlihat dari berbagai proses pekerjaan yang awalnya banyak dilakukan secara manual, kini perlahan didominasi oleh sistem terkomputerisasi. Ole (2014), Pilat et al. (2016), dan Tumbel et al. (2019) menyatakan bahwa teknologi informasi dapat meningkatkan kinerja transparansi dan akuntabilitas dalam pengelolaan keuangan daerah, walaupun Miharja et al. (2020), dan Pahlawan et al. (2020) menemukan bahwa dalam beberapa kasus teknologi informasi belum dimanfaatkan secara optimal. Dalam penyelenggaraan pemerintahan khususnya proses penatausahaan Barang Milik Negara (BMN), sistem informasi telah diterapkan untuk meminimalisir terjadinya kesalahan dalam proses penatausahaan dan untuk menjaga akuntabilitas pelaporan aset negara. Proses penatausahaan BMN sangatlah penting untuk mendukung pertanggungjawaban atas penggunaan Anggaran Pendapatan dan Belanja Negara (APBN), maka dari itu pemerintah menerapkan aplikasi Sistem Informasi Manajemen dan Akuntansi Barang Milik Negara (SIMAK-BMN) untuk membantu proses penatausahaan BMN mulai dari pencatatan, pengorganisiran, hingga ke proses penghapusan agar dapat membantu penyusunan neraca dan laporan BMN sesuai dengan ketentuan peraturan perundangundangan.

Meskipun telah dilaksanakan dengan sistem terkomputerisasi, masih terdapat kendala berupa human error yang seringkali terjadi dalam pelaksanaan SIMAK-BMN sehingga menyebabkan kurang efektifnya proses penatausahaan BMN. Salah satu cara untuk meminimalisir terjadinya human error adalah dengan teliti menjalankan sistem sesuai dengan mekanisme prosedur yang berlaku (Nafid, 2020:37), sehingga perlu dilakukan peninjauan untuk melihat kesesuaian penerapan SIMAK-BMN dengan mekanisme prosedur akuntansi BMN. Dinas Perindustrian dan Perdagangan Daerah Provinsi Sulawesi Utara sebagai unit akuntansi pada tingkat satuan kerja memegang peran sebagai Unit Akuntansi Kuasa Pengguna Barang (UAKPB) yang memiliki wewenang mengurus dan/atau menggunakan 
BMN, maka dari itu pelaksanaan SIMAK-BMN pada Dinas Perindustrian dan Perdagangan Daerah Provinsi Sulawesi Utara harus sesuai dengan mekanisme prosedur pada tingkat UAKPB yang berlaku.

\section{TINJAUAN PUSTAKA}

Sistem Informasi Akuntansi (SIA). Menurut Marina et al. (2017:32), SIA merupakan jaringan dari seluruh prosedur, formulir-formulir, catatan-catatan, dan alat-alat yang digunakan untuk mengolah data keuangan menjadi suatu bentuk laporan yang akan digunakan oleh pihak manajemen dalam mengendalikan kegiatan usahanya dan selanjutnya digunakan sebagai alat pengembilan keputusan manajemen. Tujuan pokok diselenggarakannya SIA adalah antara lain:

- Mengumpulkan dan menyimpan data tentang aktivitas dan kegiatan keuangan perusahaan.

- Memproses data menjadi informasi yang dapat digunakan dalam proses pengambilan keputusan perusahaan.

- Melakukan pengendalian terhadap seluruh aspek perusahaan.

Barang Milik Negara. Peraturan Pemerintah Republik Indonesia Nomor 28 Tahun 2020 Tentang Perubahan Atas Peraturan Pemerintah 27 Tahun 2014 tentang Pengelolaan Barang Milik Negara/Daerah mendefinisikan barang milik negara adalah semua barang yang dibeli atau diperoleh atas beban APBN atau berasal dari perolehan lainnya yang sah. Pengelolaan BMN dilaksanakan berdasarkan asas fungsional, kepastian hukum, transparansi, efisiensi, akuntabilitas, dan kepastian nilai. Sistem Informasi Manajemen dan Akuntansi Barang Milik Negara. Dalam Peraturan Menteri Keuangan Republik Indonesia Nomor 118/PMK.06/2017 Tentang Pedoman Pelaksanaan Penilaian Kembali Barang Milik Negara dijelaskan bahwa SIMAK-BMN adalah subsistem dari Sistem Akuntansi Instansi (SAI) yang merupakan serangkaian prosedur yang saling berhubungan untuk mengolah dokumen sumber guna menghasilkan informasi untuk penyusunan Neraca dan Laporan Barang Milik Negara. SIMAK-BMN dilaksanakan oleh unit organisasi akuntansi dengan prinsip-prinsip yakni ketaatan, konsistensi, kemampubandingan, materialitas, obyektif, dan kelengkapan. Dalam beberapa kasus, Rorimpandey et al. (2016) menemukan bahwa keterbatasan pengetahuan dan pemahaman sumber daya manusia dan kurangnya komitmen pimpinan SKPD dalam pengelolaan barang milik daerah pada Pemerintah Kabupaten Minahasa Selatan. Sebaliknya, Carolina et al. (2019) menemukan bahwa pengakuan, pengukuran/penilaian, dan pengungkapan aset tetap pada Badan Pengelola Keuangan dan Barang Milik Daerah Kota Manado telah sesuai dengan SAP No. 07, dan Nendher et al. (2018) menemukan bahwa proses pengelolaan Barang Milik Daerah di Dinas Pekerjaan Umum Provinsi Sulawesi Utara sudah baik. Pada kasus lainnya, Polii dan Pontoh (2018), dan Pagora et al. (2018) menemukan bahwa sistem pengendalian internal merupakan masalah utama dalam pengelolaan barang milik negara/daerah.

Prosedur SIMAK-BMN Pada Tingkat UAKPB Menurut PMK Nomor 181/PMK.06/2016 Tentang Penatausahaan BMN. Prosedur SIMAK-BMN pada tingkat UAKPB berawal dari input dokumen sumber yang kemudian akan diproses melalui entry data dan menghasilkan keluaran berupa berbagai macam buku/daftar, kartu, dan laporan. Dokumen sumber yang digunakan terdiri atas:

1. Untuk transaksi Saldo Awal, dokumen sumber yang diperlukan meliputi Buku Barang, DBKP, LBKP periode sebelumnya dan apabila diperlukan dapat ditambah laporan hasil inventarisasi BMN.

2. Untuk sumber Mutasi (perolehan, perubahan, dan penghapusan dari pencatatan), dokumen yang diperlukan meliputi Berita Acara Serah Terima BMN, dokumen 
kepemilikan BMN, dokumen pemeliharaan dan/atau pemeliharaan BMN, SPM/SP2D, Faktur pembelian, kuitansi, dokumen pengelolaan BMN, dan dokumen lainnya yang sah.

Setelah dilakukan proses penginputan dokumen sumber, prosedur pelaksanaan SIMAK-BMN dilanjutkan dengan rangkuman mekanisme sebagai berikut:

- Membukukan data transaksi BMN ke Buku Barang Kuasa Pengguna-Intrakomptabel, Buku Barang Kuasa Pengguna-Ekstrakomptabel, Buku Barang Kuasa Pengguna Bersejarah, Buku Barang Pengguna-Konstruksi Dalam Pengerjaan, Buku Barang Pengguna-Barang Persediaan berdasarkan dokumen sumber.

- Mengarsipkan dokumen penatausahaan dan dokumen pengelolaan BMN secara tertib.

- Melakukan rekonsiliasi secara periodik bersama Unit Akuntansi Kuasa Pengguna Anggaran (UAKPA) guna meningkatkan keakuratan dan akuntabilitas data transaksi BMN.

- Mencatat setiap perubahan data BMN ke dalam DBKP berdasarkan data dari buku barang dan KIB.

- Melakukan rekonsiliasi atas DBKP dengan DBMN-KD per Kementerian/Lembaga pada KPKNL, jika diperlukan.

- Melakukan pengecekan ulang kondisi BMN dan mencatat perubahan kondisi BMN yang terjadi ke DBKP, Buku Barang, dan KIB.

- Melakukan proses pencadangan (back up) data dan tutup tahun.

\section{METODE DAN TEKNIK PENERAPAN IPTEKS}

3.1. Metode Penerapan Ipteks

Metode IPTEKS yang diterapkan adalah pendeskripsian prosedur pelaksanaan SIMAK-BMN pada Dinas Perindustrian dan Perdagangan Daerah Provinsi Sulawesi Utara.

\subsection{Teknik Penerapan Ipteks}

Teknik IPTEKS yang diterapkan adalah pelaksanaan SIMAK-BMN sesuai prosedur pada tingkat UAKPB berdasarkan Peraturan Menteri Keuangan Republik Indonesia Nomor 118/PMK.06/2016 Tentang Penatausahaan Barang Milik Negara.

\section{PEMBAHASAN}

\subsection{Gambaran Objek Penerapan Ipteks}

Dinas Perindustrian dan Perdagangan Daerah Provinsi Sulawesi Utara berkedudukan di Kota Manado, Provinsi Sulawesi Utara. Dinas ini merupakan penggabungan dari Departemen Perindustrian dan Departemen Perdagangan yang sebelumnya berjalan terpisah. Setelah dilakukan penggabungan pada tahun 1966, nama instansi ini berubah menjadi Dinas Perindustrian dan Perdagangan Daerah Provinsi Sulawesi Utara. Intansi ini terdiri atas 4 bidang dan 1 Unit Pelaksanaan Teknis Dinas (UPTD) yakni Bidang Perindustrian, Bidang Fasilitasi Pengembangan Industri Kecil Menengah (IKM), Bidang Perdagangan Luar Negeri, Bidang Perdagangan Dalam Negeri, dan UPTD Balai Pengujian dan Sertifikasi Mutu Barang (BPSMB).

\subsection{Pembahasan}

Pelaksanaan SIMAK-BMN pada Dinas Perindustrian dan Perdagangan Daerah Provinsi Sulawesi Utara dimulai dengan proses penginputan dokumen sumber. Dalam proses pengadaan barang, dokumen sumber dimulai dengan pengajuan Surat Perintah Membayar (SPM) untuk pengadaan barang dan dari proses SPM menghasilkan Surat Perintah Pencairan Dana (SP2D) sebagai bentuk pengeluaran atas beban APBN untuk pengadaan barang. SP2D kemudian dicatat ke aplikasi SIMAK-BMN untuk menyusun data transaksi dan laporan BMN, setelah itu data dari aplikasi SIMAK-BMN dikirim ke aplikasi Sistem Akuntansi Instansi Berbasis Akrual (SAIBA) untuk membantu proses penyusunan laporan keuangan berbasis akrual. Kemudian data dari SAIBA dikirim ke Esalon I melalui sistem online yakni 
E-Rekon untuk merekonsiliasi data transaksi keuangan dan membantu penyusunan laporan keuangan kementrian/lembaga.

SIMAK-BMN pada Dinas Perindustrian dan Perdagangan Daerah Provinsi Sulawesi Utara telah dijalankan sesuai prosedur untuk membantu akuntabilitas pelaporan aset negara. Hal tersebut juga didukung dengan dilaksanakannya pelatihan operator SIMAK-BMN, selama dua kali dalam setahun agar lebih memahami pelaksanaan SIMAK-BMN. Namun dalam proses penginputan masih diperlukan ketelitian karena sering terjadi kesalahan dalam proses penginputan nilai harga barang yang akan berpengaruh pada laporan keuangan.

\section{KESIMPULAN DAN SARAN}

\subsection{Kesimpulan}

Pelaksanaan SIMAK-BMN pada Dinas Perindustrian dan Perdagangan Daerah Provinsi Sulawesi Utara telah sesuai dengan prosedur SIMAK-BMN tingkat UAKPB menurut Peraturan Menteri Keuangan Republik Indonesia Nomor 181/PMK.06/2016 Tentang Penatausahaan Barang Milik Negara. Namun dalam proses penginputan harus lebih diperhatikan lagi agar tidak terjadi kesalahan dalam proses pencatatan barang dikarenakan banyaknya kode dan nilai harga barang yang ada dalam sistem.

\subsection{Saran}

Proses pengarsipan dokumen fisik terkait pengelolaan BMN harus dilakukan dengan baik agar dapat dilakukan cross check sebagai bahan koreksi ketika terjadi perbedaan nilai saat penginputan harga barang dalam sistem.

\section{DAFTAR PUSTAKA}

Carolina, Manossoh, H., \& Lambey, R. (2019). Analisis perlakuan akuntansi aset tetap pada Badan Pengelola Keuangan dan Barang Milik Daerah Kota Manado. Indonesia Accounting Journal, 1(2), 74-80. https://doi.org/10.32400/iaj.26656

Marina, A., Wahjono, S. I., Syaban, M., \& Suarni, A. (2017). Sistem informasi akuntansi: Teori dan praktikal. Surabaya: UMSurabaya Publishing.

Miharja, E., Handajani, L., \& Furkan, L. (2020). Faktor-faktor yang mempengaruhi keandalan dan ketepatan waktu pelaporan keuangan pada Organisasi Perangkat Daerah Kabupaten Sumbawa Barat. Indonesia Accounting Journal, 2(2), 148-161. https://doi.org/10.32400/iaj.28818

Nafid, A. (2020). Strategi manajemen resiko dalam meminimalisir human error (Studi pada PT. BPRS Aman Syariah Sekampung). Skripsi. Fakultas Ekonomi dan Bisnis Islam, Program Studi Perbankan Syariah, Institut Agama Islam Negeri Metro, Metro. https://repository.metrouniv.ac.id/id/eprint/995/

Nendher, J., May, G., Londa, C., \& Tinangon, J. (2018). Ipteks pengelolaan Barang Milik Daerah (BMD) di Dinas Pekerjaan Umum Provinsi Sulawesi Utara. Jurnal Ipteks Akuntansi Bagi Masyarakat, 2(2). https://doi.org/10.32400/jiam.2.02.2018.21799

Ole, H. (2014). Analisis implementasi Sistem Informasi Manajemen Daerah (SIMDA) terhadap kualitas laporan keuangan SKPD (Studi kasus pada Dinas PPKAD Kabupaten Minahasa Tenggara). Jurnal Accountability, 3(2), 1-15. https://doi.org/10.32400/ja.6419.3.2.2014.1-15

Pagora, I., Pulu, E., \& Gerungai, N. (2018). Ipteks pengendalian intern atas pengelolaan Barang Milik Daerah di Dinas Komunikasi Informatika Persandian dan Statistik Daerah Provinsi Sulawesi Utara. Jurnal Ipteks Akuntansi Bagi Masyarakat, 2(2), 585589. https://doi.org/10.32400/jiam.2.02.2018.21836 
Pahlawan, E., Wijayanti, A., \& Suhendro, S. (2020). Pengaruh kompetensi aparatur desa, sistem pengendalian internal, pemanfaatan teknologi informasi dan partisipasi masyarakat terhadap akuntabilitas pengelolaan dana desa. Indonesia Accounting Journal, 2(2), 162-172. https://doi.org/10.32400/iaj.29261

Peraturan Pemerintah Republik Indonesia Nomor 28 Tahun 2020. Perubahan atas Peraturan Pemerintah Nomor 27 tahun 2014 tentang Pengelolaan Barang Milik Negara/Daerah. Presiden Republik Indonesia.

Peraturan Menteri Keuangan Republik Indonesia Nomor 118/PMK.06/2017. Pedoman Pelaksanaan Penilaian Kembali Barang Milik Negara. Menteri Keuangan Republik Indonesia.

Peraturan Menteri Keuangan Republik Indonesia Nomor 181/PMK.06/2016. Penatausahaan Barang Milik Negara. Menteri Keuangan Republik Indonesia.

Pilat, J., Sondakh, J., \& Manossoh, H. (2016). Analisis penerapan Sistem Informasi Manajemen Daerah (SIMDA) keuangan dalam pengelolaan keuangan daerah Pemerintah Kota Manado. Jurnal Accountability, 5(2), 72-83. https://doi.org/10.32400/ja.14426.5.2.2016.72-83

Polii, I., \& Pontoh, W. (2018). Ipteks pengendalian intern SIMDA keuangan dalam pengelolaan data keuangan pada Badan Perencanaan Dan Pembangunan Daerah (BAPPEDA) Provinsi Sulawesi Utara. Jurnal Ipteks Akuntansi Bagi Masyarakat, 2(2), 246-250. https://doi.org/10.32400/jiam.2.02.2018.21743

Rorimpandey, A., Nangoi, G., \& Manossoh, H. (2016). Analisis pengelolaan Barang Milik Daerah menurut Peraturan Pemerintah Nomor 27 tahun 2014 pada Pemerintah Kabupaten Minahasa Selatan. Jurnal Accountability, 5(2), 168-177. https://doi.org/10.32400/ja.14433.5.2.2016.168-177

Tumbel, J., Pangemanan, S., \& Alexander, S. (2019). Penerapan sistem akuntansi keuangan daerah pada Badan Perencanaan Penelitian dan Pengembangan di Kabupaten Minahasa Selatan. Indonesia Accounting Journal, 1(2), 120-128. https://doi.org/10.32400/iaj.26815 